\title{
THE SUBJECTIVELY ENDURING SELF
}

\author{
L. A. Paul
}

\section{Forthcoming (2016) in The Routledge Handbook of the Philosophy of Temporal Experience, edited by Ian Phillips.}

The self can be understood in objective metaphysical terms as a bundle of properties, as a substance, or as some other kind of entity on our metaphysical list of what there is. Such an approach explores the metaphysical nature of the self when regarded from a suitably impersonal, ontological perspective. It explores the nature and structure of the self in objective reality, that is, the nature and structure of the self from without. This is the objective self. $^{\text {ii }}$

I am taking a different approach. In addition to objective reality, which is usually understood and explored from an impersonal, quasi-observational and metaphysically realist perspective, we can also explore the nature and structure of subjective reality. The nature and structure of subjective reality is defined by the nature and structure of firstpersonal, conscious experience. Subjective reality is as real as objective reality, and a metaphysical realist such as myself can endorse the existence of both kinds of ontology. The mental states that, as experienced from the first-personal or subjective perspective, capture the nature and structure of subjective reality, are included in objective reality. ${ }^{\mathrm{iii}}$ The questions to explore in a subjective ontology of the self concern the nature and structure of the self from the first-personal or subjective perspective, that is, the nature and structure of the self from within. This is the subjective self. ${ }^{\text {iv }}$ 
In this paper, I will explore the ontology of the subjectively enduring self, an ontology that is structured by one's subjective temporal experience and imaginative identity with one's first-personal, conscious perspective in the present, the (near) past, and the (near) future. My thesis is that the subjective self endures, at least for short (but still relatively substantial and extended) stretches. Implicitly, I will assume that an enduring subjective self is consistent with a perduring, four-dimensional objective self. (An enduring self persists through time such that the very same, wholly present self exists at different times. A perduring self persists through time by being a sum of appropriately related but different temporal parts at different times. Subjective endurance is consistent with objective perdurance.)

\section{A first-personal perspective on oneself}

Intuitively, the distinction between the subjective perspective of the self and the objective perspective on the self mirrors a distinction between perceptual perspectives I can have. ${ }^{\mathrm{v}}$ An example will help to bring out the point.

Some contemporary computer games are "first-person shooter" (FPS) games where you, the agent, have some sort of task to perform. When you play the game, you play as though you were looking out of the eyes of your character. Your line of sight is the one the character you are playing has. You are presented as seeming to hold a weapon, you "turn your head" to gain a line of sight, etc. In general, you know where you are from the first-personal perspective of your character, the character whose "boots" you are occupying as you play the game. You are given an artificial simulation of the firstpersonal perspective of your character using a visual line of sight, as a first-personal, 
subjective way for you to know who you are and where you are in the game. ${ }^{\mathrm{vi}}$ In this way, you are immersed in the game. This game perspective is analogous to the subjective perspective.

However, as you play, you have additional information: a different way in which you know which character you are and where you are on the terrain. This information comes from an inset in the frame, where you can see yourself "from above", more or less like you can see yourself represented by a moving dot when you locate yourself using a map application on your phone. The inset simulates a third-personal visual perspective, from above, on your game character, and by watching it you also know who you are and where you are. Your information about yourself from this perspective is merely observational, in that it comes from positional and other descriptive information that anyone could access to in order to locate you in the gameworld. This game perspective is analogous to the objective perspective.

Another way to illustrate the distinction comes from Google Maps. If you use Google Maps under the "map view" setting, you'll see where you are from above, with your location represented as a blue dot moving along the map. If you switch to the "street view" setting you drop down to street level. Once you are in the street view mode, you see where you are by occupying a perspective you'd have by being on the street at that location. The view from above, using map view, intuitively corresponds to the (abstract) perspective we take when we explore objective ontology. It's an observer's view of the mapworld with a center (you).

With this idea in hand, the ontological perspective on the self can be defined as the observational perspective. It is analogous to the perspective you take when you are 
looking at the centered map of reality from above. The subjective perspective from the self,, on the other hand, corresponds to the view from within the centered mapworld. That can be defined as the agential perspective, which is the perspective we need to explore in order to limn the nature of subjective reality. It is an exploration of reality from within, as an experiencer, rather than an exploration of reality from without, as a detached observer.

\section{Temporal prospection}

We understand ourselves as persisting selves by understanding ourselves as temporally extended entities existing at different points of time (Paul 2014a). Prospective assessment using a kind of perspectival reasoning plays a role in reasoning about ourselves (as well as about others).

[These] combined observations suggest that the core network that supports remembering, prospection, theory of mind and related tasks is not shared by all tasks that require complex problem solving or imagination. Rather, the network seems to be specialized for, and actively engaged by, mental acts that require the projection of oneself into another time, place or perspective ... by projecting our own mental states into different vantage points, in an analogous manner to how one projects oneself into the past and future (Buckner and Carroll 2006: 53). ${ }^{\mathrm{vii}}$

When we mentally project ourselves into the past and future, how do we represent ourselves? The question arises because when we understand ourselves to exist at different points in time, there are different ways to mentally project the self into the future or the 
past. Is the mental projection framed from an observational perspective, where I model the mind of my future or past self more or less in the same way I'd model the mind of another person? Or do I model my past or future self empathetically, that is, from the inside or agentially, attempting to occupy my point of view at that time as my point of $v i e w$ ? We seem to use both types of representation. You can represent yourself in the past and in the future from an observational perspective, that is, from an external or more impersonal perspective analogous to a perspective that observes your game character from above, as an icon on the game map. Or you can represent yourself in the past and in the future from an agential or "through the eyes of the agent" perspective, that is, from the internal agential perspective analogous to your perspective as a character immersed in the game.

\section{The window of the self}

One factor that can influence the nature of how we represent ourselves at different times is the temporal distance of my past and future selves from my current self. When I, at a time, represent my future self in the distant future, I am more likely to represent myself using the observational stance. When I represent a distant past self, I am also more likely to represent myself using the observational stance.

This can be overcome. Sometimes it takes imaginative effort, but sometimes not. If I have an experience that triggers an episodic memory, for example, taking a bite of a cookie whose taste transports me back to my childhood, I can easily represent my past self from my agential perspective, as though I were eating the cookie at my aunt's knee

and looking up at her. ${ }^{\text {viii }}$ (I can also represent myself observationally in episodic memory, 
where I seem to observe myself as a child having the cookie at my aunt's knee, but I don't represent this as looking out from my childlike perspective.)

We do, however, take the agential perspective very naturally under certain circumstances. My representation of myself in my immediate future, as well as in my immediate past, is much more likely to be agential. As Pronin and Ross (2006) show, we tend to represent ourselves agentially in the immediate past, but even a temporal distance of a day can increase the degree of observational representation. ${ }^{\text {ix }}$ Similarly, when we think of ourselves in our immediate future, we tend to represent ourselves agentially, but as we imaginatively increase the temporal distance to a future self, we shift towards an observational representation. Your imaginative representation of yourself and what you'll be doing 30 seconds from now is much more likely to represent the world and yourself as though you are, metaphorically, looking out from your own eyes. That is, at this temporal distance, you can naturally and easily represent yourself from your agential, first-personal perspective. Your episodic memory of yourself in your immediate past, say, 30 seconds ago, is also much more likely to be a representation of yourself from your agential, firstpersonal perspective.

We can think of the structure of this feature of subjective reality as a window to the past and to the future framed from the agential, first-personal perspective. The window is typically small. As I'll explore below, it also requires an implicit assumption that there isn't too much change in the nature of your first-personal experience over its temporal extent. Thinking about yourself persisting through time within this temporal window involves understanding yourself first-personally at the times within. It's also important that this is a default way to understand yourself as persisting in these nearby, 
short, temporal stretches. You don't need to make any special effort to adopt the agential perspective here. It's just a natural way to represent your near temporal selves.

When we think of our future selves first-personally in this way, we prospectively represent the first-personal perspective of our future self at that time. When we think of our past selves first-personally, we retrospectively represent the first-personal perspective of our past self at that time. This involves thinking about or recalling our past firstpersonal agential perspectives as well as reflecting on our future agential point of view. In the short term, how I represent myself and my agential perspective stays relatively constant as I project myself forward within the agential temporal window. And the way I represent being me will also stay largely constant as I retrospectively project myself backward and recall my experiences within my agential temporal window.

\section{Temporal Empathy}

Temporally forward projection of one's first-personal point of view is an anticipatory and imaginative act of prospective representation. Temporally backward projection of one's first-personal point of view is a memory-like and imaginative act of retrospective representation.

As I define them, both types of representation are assessments "from the inside". Prospective representation involves taking the agential perspective on one's future self. When you prospectively assess, you grasp your future first-personal perspective at time $t$ from your current first-personal perspective. You represent salient features of how you'll actually experience who you'll be. So, ideally, what you want to represent is the subjective, first-personal, experiential character of what it will be like to be you at $t^{\mathrm{x}}{ }^{\mathrm{x}}$ You 
want to represent what it will be like to be you "from the inside" at $t$, that is, you want to represent what it will be like to be you then, just as you know what it is like to be you now.

One way to put the point is that you want to project your current first-personal perspective, your perspective as it is now, into your future self (but adjusted given any relevant changes in circumstances and mental states). If you can project in this way, at least along some relevant experiential dimension, you can have the capacity to empathize with your future self. The kind of empathy you want is the rich, cognitive sort, not mere affective empathy where you simply know how you'll feel. You want the sort of empathy that you can use to generate a cognitively rich representation of your future agential perspective. This isn't merely an affective response to who you'd be. With a cognitive type of empathy, you can imagine your future agential perspective in all its cognitive richness, as understood through the lens of your current agential perspective, adjusted for changes in circumstances. ${ }^{\mathrm{xi}}$

Above, I described the nature of prospective assessment as anticipatory and imaginative. The anticipatory element comes from your anticipation of changes and future events. The imaginative element comes from a distinctive feature of prospective representation: when we prospectively represent our future selves we imaginatively occupy our future agential points of view. This can be described metaphorically, where we think of ourselves as "stepping into the shoes" of our future self, by imagining being that future self from that future self's agential standpoint. We imaginatively take on that self's point of view as our own. ${ }^{\text {ii }}$ We can take this to be a kind of cognitive empathy for a future self, because we take our current agential point of view and attempt to use it to 
represent our future agential point of view. In this sense, we prospectively empathize with our future selves in order to understand them. I understand enough about my future self, using my current first-personal conscious perspective, to imaginatively represent myself as sharing an agential point of view with that self. In this sense, I can imagine myself as occupying or embodying this future self. One reason this can be valuable is that by performing the imaginative simulation I can discover or understand more about my future properties.

My prospective representation thus involves a kind of capture of the first-personal or subjective point of view of my future self. Part of the empathetic act involves representing the nature and character of my future lived experience as I will experience it. That is, I imaginatively experience myself engaging in near future events from my firstpersonal agential perspective, where the first-personal perspective I have now is qualitatively continuous with the agential perspective I occupy in my imagined future experience. $^{\text {xiii }}$

Retrospective representation also captures my agential perspective. When I retrospect, I imaginatively evolve my present first-personal perspective back to my past first-personal perspective, adjusting for any changes in circumstance. This imaginative act draws on my memory of the nature and character of my past lived experience, that is, what it was like to be me then. I cognitively empathize with my past self, representing my past self's first-personal or agential perspective on that situation. In this sense, I "occupy the shoes" of my past self. Again, when I retrospect, I imaginatively represent myself as I experienced that past event, where my current agential perspective is effectively continuous with the agential perspective I took in the past when engaging in that activity. 
I recall engaging in the event via remembering my experience, and I empathetically represent my first-personal agential perspective.

In each kind of temporally empathetic representation of myself, I represent myself from my agential perspective in the near past or near future. My first-personal, agential simulation is constant (at least in essentials) and experienced as shared through the past and future times within my agential temporal window.

\section{The enduring self}

My representation of the point of view of my future self (and mutatis mutandis of my past self) through my agential window gives me a distinctive kind of understanding of myself as an enduring self in the near future and near past. ${ }^{\text {xiv }}$ How?

Start by making some simplifying assumptions about objectively persisting conscious individuals. Assume that the basic objective ontological structure of such individuals is grounded by a series of temporal stages related by appropriate genidentity relations. (Genidentity relations are (usually successive) causal or qualitative relations between temporal stages of a persisting object.) Objective perdurance comes from summing the stages. Objective (qualitative) endurance comes from any partial objective qualitative overlap of these stages. ${ }^{\mathrm{xv}}$

The structure of subjective endurance for an individual, on the other hand, is grounded by the nature of her first-personal experience. Take the subjective temporal unit of agential experience for a self to be defined by her specious present (Phillips 2010). At subjectively near times, I naturally represent my first-personal perspective as a continuously enduring agential perspective from the near past, through the specious 
present, into the near future. The nature and character of my experience is as of being the very same enduring self, that is, as of qualitative continuity (with respect to sameness of agential perspective), from the inside, through my temporal window.

The representation relies on the empathetic ability of my current self to (imaginatively) see the world through the eyes of my near past and near future selves, where I represent myself as experiencing the qualitatively same agential perspective throughout my temporal window. This structures my experience as a subjectively enduring point of view, or as a subjectively enduring self. ${ }^{\mathrm{xvi}}$ That is, this is the subjective ontological foundation for the subjective endurance of the self. ${ }^{\text {xvii }}$ An important feature of what matters here is that taking the agential perspective, within this window, is the default perspective. This is why endurance of my agential perspective seems like such an intuitive and natural way to understand persistence. It's my default mode for the continuous experience of my point of view as I persist through short periods of time.

As time passes, my current self and its temporal endurance window advances. ${ }^{\text {xviii }}$ As the nature and character of my first-personal perspective gradually evolves, at some point I can no longer seamlessly represent past agential perspectives as continuous with my own, current agential perspective. Once this happens, it is natural to shift to an observer's perspective on those earlier selves.

Gradual change in the nature of my near temporal experience is consistent with my having the qualitatively same agential perspective throughout a short subjective temporal extent. (For example, I retain my first-personal perspective and identify as the same subjective self from moment to moment as I move around or experience other inessential changes.) However, over time, gradual change can accumulate such that I no 
longer stand in the same-self relation to a past self. (More radical change can also cause this.)The same-objective-self relation in objective reality is intransitive, and can be manifested when selves (composed of temporal stages) that compose a person objectively change in some significant way over time. The transitivity of the same-subjective-self relation in subjective reality fails when I can no longer subjectively represent my past self or my future self as the same self I am now. It occurs when the subjective character of the agential perspective of that past self or that future self is too qualitatively or phenomenally different from my current agential perspective.

\section{Future-blocked}

I have argued elsewhere (Paul 2014b; Paul 2015a) that you can lack the imaginative capacity to first-personally represent possibilities for your future self in contexts of transformative choice. If you face an experience that will transform you both epistemically and personally, defined as a "transformative experience", before you actually have that experience you may not have epistemic access to your future self's agential perspective. You can't imaginatively model or simulate the way you will firstpersonally respond to the experience and the resulting future circumstances. The thesis is explicitly Lewisian: an experience of that kind is needed to give the experiencer the ability to imagine, recognize, and cognitively model her possible future selves (Lewis 1990).

The deep issue with respect to subjective selves is that we need the right sort of understanding, in terms of prospective assessment, in order to imaginatively project ourselves forward as enduring selves into the future. We also want to retain an 
understanding of our past selves that allows us to retrospectively assess ourselves as enduring through change. My ability to empathetically grasp my other selves in a way that represents my agential point of view as enduring is what makes those other selves cognitively mine. That is, I intuitively understand, given the shared character of my agential perspectives, these past and future selves as me. The kind of psychological access I want to my future self and past self, where I can empathetically occupy my firstpersonal perspective, is nicely captured by David Velleman:

The future "me" whose existence matters [to me] is picked out precisely by his owning a point of view into which I am attempting to project my representations of the future, just as a past "me" can be picked out by his having owned the point of view from which I have recovered representations of the past (2006: 76).

The problem is that transformative experience can disrupt this first-personal agential access to our past, future, and even merely possible selves.

The central examples are those that scale: an experience that is so dramatically epistemically transformative that it carries with it significant first-personal change, making it personally transformative. Examples include a case where you could choose to become a cyborg by getting a neural chip that will give you an unknown, new sense capacity but take away your sense of taste. Another case concerns a congenitally blind adult choosing to have a retinal operation to become sighted. Another much-discussed example involves a person choosing to have her first child (Paul 2015a, Paul 2015b). The idea is that, in such cases, you can't know what it will be like to have the experience 
before you have it, and if you choose to have it, it will change the nature of your firstpersonal or agential perspective.

While the claims about transformation are more controversial in some cases than in others, the basic idea is this: experience, especially intense experience, can affect a person's representational capacities and her first-personal preferences. Experience can transform us in a rich, psychologically representational way. What happens to us can affect and control our point of view, because it can affect our preferences and how we model and represent the world and ourselves. On this view, preferences are psychologically real mental states that structure an agent's phenomenology, intentional states, and first-personal perspective on the world. An epistemic transformation can transform an agent's abilities and inclinations, and by extension, her preferences and the nature of her agential perspective.

As a result, if we are facing the possibility of significant epistemic transformation, we are facing the possibility of significant self-change. If, because we lack the requisite experiential knowledge, we cannot prospectively assess the nature of the epistemically transformative experience before we undergo it, we cannot prospectively simulate our response from our current first-personal perspective to having an experience like this, and by extension, cannot prospectively model who we'll become ${ }^{\text {xix }}$ If you can't firstpersonally model the nature of the experience you'll have, you can't first-personally assess your response to the experience. ${ }^{\mathrm{xx}}$ You can't model your responses in a way that will allow you to "see" your future agential perspectives, the perspectives that could result from your experiences. ${ }^{\text {xxi }}$ When the experiences are high-stakes, life-defining 
experiences, the problem extends past merely being unable to assess the immediate future outcomes of your choice to being unable to assess who you'll become.

To explore this idea a bit more, let's discuss the case of a congenitally blind adult who wants to have retinal surgery in order to be able to see. Imagine that he is a saxophone player, and has built his life around his blindness, choosing a career and a way of living and understanding the world through touch and sound. His soulful music reflects the rich detail that his highly trained auditory capacities give to his lived experience. His dominant sense modality is audition, and thus his way of living in the world is deeply influenced by his blindness. Like all of us, his lived experience is structured by his way of experiencing the world through his senses, especially his dominant sense modality. This affects the details of his life and lived experience, from the way he organizes his day to the way he navigates his environment and understands the world around him.

In our example, the saxophonist doesn't know what it is like to be sighted, and so he can't simulate his possible future (sighted) self after the operation. He thinks he'd be happier if he were sighted, but he knows he will change along many dimensions. Since he can't know what it will be like to be sighted, he cannot use imaginative projection to determine the nature of his future as a sighted person from his agential perspective.

The problem for the saxophonist is that there is an epistemic wall created by the transformative nature of the experience involved in the choice, one that blocks a role for his first-personal perspective in evaluating and assessing his future self from the agential perspective. Experience of a certain sort is required for him to be able to imagine his future point of view. 
It's of course possible for him to be informed, via testimony and description, of the value (or utility) for him of possible ways he'll experience the future. The trouble is that this will not help him to imagine the nature of his future lived experience from the agential perspective.

We can see this if we think of the kind of experiential content he must be able to represent in order to prospectively represent his future agential point of view. As I argued above, for a person to imaginatively represent himself as enduring into the future, he must be able to prospectively assess his future point of view. Here, knowing the relevant testimony about his future lived experiences isn't enough for him to be able to imagine his future agential perspective. To grasp the subjective, first-personal perspective of his future (sighted) self, he needs to have the experience of being sighted.

What it's like to be the saxophonist (before the operation) defines his firstpersonal subjective self, and what it will be like to be him will define his future subjective self. The blind saxophonist's inability to simulate his future lived experience as a sighted individual arises from the fact that he cannot accurately determine, via simulation or imaginative representation, what it will be like for him to see. For this reason, he cannot accurately determine, via simulation, how he'd respond to the experience of seeing. As a result, before the operation, he cannot accurately imagine the nature of his future lived experience from his agential perspective.

One problem he faces arises from the epistemic transformation that gaining visual information would involve. The second problem the saxophonist faces is that the dramatic nature of the new experience, becoming sighted, scales up into a change in selfdefining experience. Once he becomes sighted, he will no longer have hearing as his 
dominant sense modality. Once he stops relying on auditory cues the way he did before having visual information inform his experiences, his knowledge of the world and his relation to it will change in dramatic ways. This suggests that the nature and character of his agential perspective will also change. If so, he cannot project himself forward as an enduring self through the change. ${ }^{x x i i}$

Because of the massive epistemic change in his future, the blind saxophonist, before the operation, lacks the ability to mentally look forward and prospectively imagine his future, sighted agential perspective. The source of his epistemic failure is the transformative nature of the experience: changing his dominant sense modality also changes his psychological capacities and states. ${ }^{\text {xiii }}$ Before he becomes sighted, empathetic identification of his current agential perspective with the first-personal perspective of his future, sighted, self is impossible, because he lacks the abilities and information he needs to be able to perform the empathetic task. Without the ability to empathetically model his future self along the dimension that is central to the self-change involved, the blind saxophonist cannot prospectively assess his future lived experience as a sighted person. In this sense, he cannot project himself into the future. In the most personal sense possible, he cannot prefigure his future self.

We can all find ourselves in the position like that of the saxophonist. If you face a transformative experience, it is as if you face a blank concrete wall. You can't see what lies beyond. Perhaps you know that whatever happens in the future, past the wall, will involve you somehow. You know you'll be there, in that future moment, living that future experience. But you don't know what it will be like to be that self. Your enduring self is lost in the vast emptiness of the ungraspable future. ${ }^{\text {xxiv }}$ 


\section{References}

Benovsky, J. (2009) "The Self: A Humean Bundle and/or a Cartesian Substance?," European Journal of Analytic Philosophy 5 (1), 7-19.

Buckner, R. L. and Carroll, D. C. (2006) "Self-Projection and the Brain," Trends in Cognitive Sciences 11 (2), 49-57.

Carr, J. (2015). “Epistemic Expansions.” Res Philosophica 92 (2): 217-236.

Dainton, B. (2000) Stream of consciousness: Unity and continuity in conscious experience, London: Routledge.

De Brigard, F. et al. (2015) "Neural Activity Associated with Self, Other, and Objectbased Counterfactual Thinking," Neuroimage 109, 12-26.

Hoerl, C. and McCormack, T. (2016) "Making Decisions about the Future: Regret and the Cognitive Function of Episodic Memory," in K. Michaelian, S. B. Klein and K. Szpunar (eds) Seeing the Future: Theoretical Perspectives on Future-oriented Mental Time Travel, Oxford: Oxford University Press.

Jackson, F. (1982) “Epiphenomenal Qualia,” Philosophical Quarterly 32, 127-136.

Lewis, D. (1990) "What Experience Teaches," in W.G. Lycan (ed.) Mind and Cognition, Blackwell.

Loar, B. (1990) "Phenomenal States," Philosophical Perspectives 4, 81-108.

Makati, R., Tamir, D. and Morelli, S. (2016) "Lay Beliefs about the Effects of Perspective-taking on the Self," Unpublished poster presentation at: Association for Psychological Science, May 26-29 2016, Chicago, United States.

Mitchell, J. P., Schirmer, J., Ames, D. L., and Gilbert, D. T. (2011) "Medial Prefrontal Cortex Predicts Intertemporal Choice," Journal of Cognitive Neuroscience 23 (4), 1-10.

Nagel, T. (1986) The View from Nowhere, Oxford: Oxford University Press.

Paul, L. A. (2002) “Logical Parts,” Noûs 36 (4), 578-596.

---- (2014a) "Experience and the Arrow," in A. Wilson (ed.) Chance and Temporal Asymmetry, Oxford: Oxford University Press. 
----- (2014b) Transformative Experience, Oxford: Oxford University Press.

---- (2015a). "What you Can’t Expect when you're Expecting." Res Philosophica 92, 149-170.

----- (2015b). “Transformative Choice: Discussion and Replies," Res Philosophica $92,473-545$.

----- (Forthcoming 2017). "De Se Preferences and Empathy for Future Selves," in J. Hawthorne (ed.) Philosophical Perspectives: Metaphysics.

Phillips, I. B. (2010) "Perceiving temporal properties," European Journal of Philosophy 18(2), 176-202.

Phillips, I. B. (2014) “The temporal structure of experience," in D. Lloyd and V. Arstila (eds) Subjective Time: the Philosophy, Psychology, and Neuroscience of Temporality Cambridge, MA: MIT Press, pp. 139-158.

Pronin, E. and Ross, L. (2006) "Temporal Differences in Trait Self-Ascription: When the Self is Seen as an Other," Journal of Personality and Social Psychology 90 (2), 197-209.

Saxe, R. (2005). "Against simulation: the argument from error," Trends in Cognitive Sciences 9(4), 174-179.

Tulving, E. (1972) "Episodic and Semantic Memory," in E. Tulving and W. Donaldson (eds.) Organization of Memory, New York: Academic Press.

----- (1983) Elements of Episodic Memory. Oxford: Oxford University Press.

Velleman, D. (2006) Self to Self: Selected Essays, Cambridge: Cambridge University Press.

Watzl, S. (2013) "Silencing the experience of change," Philosophical Studies 165, 100932 . 
ii For example, (Benovsky 2009).
iii We might model the subjective-objective distinction on Brian Loar's distinction between the phenomenal
mode of presentation and the scientific mode of presentation (Loar 1990).
iv We can think of the subjective self as an entity that is subjectively real and numerically distinct from the
objective self that is objectively real, or we can think in terms of a subjective ontological perspective on the
self (the self from the inside) and the same self as explored from an objective ontological perspective (the
self from the outside). I'm inclined to think of the self in terms of the latter conception but I won't
distinguish between these two conceptions here.
${ }^{v}$ The locus classicus for discussion of this issue in the philosophy of mind is Nagel's View From Nowhere (Nagel 1986). But Nagel's point concerns physicalism, which is not at issue here. Subjective reality does not concern primitive mental states: from the objective ontological perspective, the mental states that represent an individual's subjective reality are fully realized by more fundamental physical states.

${ }^{v i}$ Which, of course, you grasp from your own first-personal perspective.

vii I am not inclined to interpret prospective and retrospective simulation or imagination in an overly strong way. For discussion, see (Saxe 2005; De Brigard et al 2015).

viii This is, of course, the famous Proustian moment with the madeleine, now immortalized in American culture by Starbucks and various other companies. For classic treatments of episodic memory and selfprojection, see (Tulving 1972; Tulving 1983).

${ }^{\mathrm{ix}}$ See especially (Pronin and Ross 2006: 203 Study 4 and Figure 4). Also see (Makati et al 2016).

${ }^{x}$ There is a clear parallel to the discovery that Mary makes when she leaves her black and white room and discovers what seeing red is like (Jackson 1982).

xi There's a bit of hedging I'm doing here. The core features of my first personal perspective have to remain enough the same over the temporal window for my agential perspective at each time to count, in terms of my experience, as being the same (or representing the same) agential perspective. Inessential changes are OK. But which features are core? How much change is too much change? It's not clear. In any case, when we believe we are prospecting accurately, so we believe we are actually imagining what it will be like to be our future self, we are preserving the relevant core features in the imaginative act. There's more to say here (see Paul 2002 for related discussion) but it's for another paper.

xii I will use the term "imagine" in a broad sense that is consistent with the way many contemporary psychologists would use the term. So while visual imagination is covered by my use of the term, I am taking "imagining" to be an act that involves cognitive modeling of possible situations, which would include modeling without explicit visual imagery. Imagination may or may not involve sensory imagery, and any simulation involved is likely to occur only with the level of detail needed to make the intended projective assessment (Saxe 2005).

xiii Of course, "perspective" and "point of view" need not be understood visually. The projection of my current perspective into my future perspective does not need to involve the representation of sensory images, although it might. And the projection does not have to be at a particularly fine level of detail. ${ }^{x i v}$ This is a kind of understanding that I value and use to structure my life and to interpret my lived experience over time. See (Paul forthcoming).

${ }^{x v}$ For my preferred account of objective endurance and perdurance, see (Paul 2002: 585-9), where I develop and defend the notion of partial qualitative overlap for persisting objects.

xvi Also see Phillips 2014, Dainton 2000, Watzl 2013.

xvii This kind of representation extends to my merely possible selves at near possible worlds. From my agential perspective I imaginatively represent the perspectives and lived experiences of transworld identical merely possible selves, that is, I simulate who I could become or who I might have been under different circumstances in a non-counterpart theoretical way.

xviii The agential perspective is not confined to this temporal window. We can use empathetic memory and anticipation to retrospectively leap to a more distant past or prospectively leap to a more distant future. The window just defines the temporal extent of our ordinary, effortlessly agential subjective perspective.

${ }^{x i x}$ For some representative research on how the inability to model one's future self can lead to poor decisions, see (Mitchell et al 2011).

${ }^{\mathrm{xx}}$ Also see (Carr 2015).

${ }^{\mathrm{xxi}}$ As I noted above, the more remote your future or past self is from who you are now, the more likely you are to model your self from the third-personal, or "detached" perspective. Normally, this remoteness is temporal: you are more likely to think of yourself in the third-person when you think of yourself in the 
distant future or in the distant past, as opposed to the immediate past or future (or the present). But temporal distance is only contingently related to the possibility of the first-personal inaccessibility of our selves. Instances of episodic memory (think of Proust's example of the madeleine, which transports him into his first-personal perspective as a child) or holding fixed key internal representational features can help us to imaginatively occupy the first-personal perspectives of temporally distant selves. And dramatic change, even over the short term, can make a temporally immanent self seem remote. (The same distinction can hold with respect to modality, that is, with respect to possible selves.) The inaccessibility of one's future first-personal perspective across large temporal or modal distances is part of what can make those decisions hard (at least if one wants to choose prospectively, rather than just "picking" or effectively flipping a coin.

${ }_{\text {xxii }}$ See (Hoerl and McCormack 2016) for a very interesting discussion of episodic memory, mental timetravel, and the anticipation of regret in the context of transformative experience and transformative decision-making.

${ }_{x x i i i}$ In (Paul 2014), I argue that this creates a problem for a model of rational choice based on maximizing one's expected utility when making life-changing choices. An agent facing transformative change cannot model the preferences and utilities of her epistemically inaccessible possible future selves. Thus, she cannot represent expected utilities for the acts that would bring about these selves, and so she cannot represent the possibilities in a way that will allow her to make a rational choice between outcomes involving significant self-change.

xxiv Thanks to Ross Cameron, Trenton merricks, and Ian Phillips for comments and discussion. 